\section{THE VETERINARIAN AND THE COLONIES}

$\mathrm{M}$ AJOR J. M. SMITH, who was formerly chief veterinary officer to the Department of Agriculture and Fisheries, Government of Palestine recently gave to the National Veterinary Medical Association of Great Britain and Ireland a valuable address on the part played by the veterinarian in the development of our Colonies (Vet. Rec., 55, 415; 1943).

Colonial development requires, he said, many specialists. The population of the Colonies are usually natives with a pastoral economy, which is sometimes nomadic. Cattle are the wealth of the community, and tribal influence often depends on the number of cattle possessed by the tribe. Improvement of the existing agricultural methods results in more settled communities, better trade and food production and increase in the population, with higher standards of health among the people and their domestic stock. Development of trade requires development of trade routes and of means of transport, and these require further measures of health control. It is clear that the veterinary surgeon taking part in developments of this kind has to adapt himself to conditions very different from those prevailing in the British Isles.

Like the missionary, administrator and the medical man, he must try to understand the people and their customs; he must also study the elimate and the wild and domestic animal life. Major Smith says that, after some years of work of this kind, the chief contagious diseases of cattle are being gradually controlled in our Colonies ; from some of them they have been eradicated. Parts of Africa, however, still await general development. Not all Colonies give the veterinary officer his due; not all of them realize how useful he can be. Major Smith tells us exactly how he can help the administrator.

His first function must be active work in the field and research in the laboratory on rapidly spreading contagious diseases such as rinderpest, trypanosomiasis, tuberculosis, anthrax and swine fever. The amount of work involved is indicated by the fact that in Nigeria in 1941433,000 cattle were vaccinated and 182,000 temporarily immunized against rinderpest, while 300,000 were vaccinated against blackquarter and 500,000 against hæmorrhagic septicæmia. By selective breeding, elimination of inbreeding and castration of inferior stock the general level of livestock is being improved. Artificial insemination is being used on a small scale in Kenya and Palestine with encouraging results. Improvement of stock creates demands for movement of stock over great distances, and trade routes for these movements have to be guarded against disease by inspection, regulations and research. When trade in hides, skins, ghee, butter and similar products develops, the veterinary officer must help the native to improve the production of these. In Uganda, for example, the value of exported hides and skins in 1939 was about $£ 90,000$; in 1941 it was $£ 140,000$. Similar increases have occurred in Kenya and Nigeria. In some Colonies dairying has become a valuable industry. Kenya, for example, produced, in $1940,3 \frac{1}{2}$ million pounds of butter and 300,000 pounds of cheese. The commercialization of the native ghee, made by extracting the fat from milk, has resulted in a large export trade in this for Kenya, Nyasaland and
Tanganyika Territory. Other Colonies await similar development.

The export of cattle and meat from Colonies where east coast fever and contagious bovine pleuropneumonia flourish is difficult or impossible; other countries will not import such stock. Some Colonies afflicted with such diseases have, therefore, fallen back on the production or export of canned and frozen meat produced in their own plants. Efficient meat inspection by veterinary officers is demanded by the importing countries and is, indeed, essential to the production of meat for human consumption. To he'p in this work selected natives are being educated in Kenya and Nigeria in the use of simple veterinary equipment and in the administration of drugs by the mouth and of sera and vaccines and in animal husbandry.

In most of our Colonies, veterinary departments have now been established and these are in no way subordinate either to the agricultural or the medical departments; the pay and conditions of service of their personnel compare favourably with those of the medical, legal, engineering and other professional services. This is as it should be everywhere. Major Smith thinks, however, that the great work being done by the colonial veterinary officer will be greater still in the future. He concludes his address with his views upon these future developments. Among future colonial problems he mentions the tackling of diseases of farm stock which are still causing enormous financial losses at home, and the prevention of the entry of these into our Colonies, improvements in the housing and feeding of animals and in the killing centres and meat production plants, the organization and establishment of dairies and the maintenance of the health of the increased animal populations. The broadening of veterinary education, the co-operation of the universities and the aid of the Government will all be required if we are to educate rightly the right sort of men for this important colonial work.

Contributors to the interesting discussion which followed the address showed substantial agreement and some amplification of it. Among the speakers were Mr. John Smith, adviser in animal health to the Colonial Office; Sir Arthur Olver, principal of the Royal (Dick) Veterinary College; Prof. Kearney of Dublin, and other veterinarians who have had long experience of veterinary administration and practice in Egypt, the Sudan, India, Kenya, Nigeria, West Africa and South Africa. We cannot summarize their remarks here, but it is pertinent to mention Sir Arthur Olver's reference to the work of Sir Arnold Theiler in South Africa and of Dr. Moehler in the United States. The work of both these men, said Sir Arthur, has revolutionized the agricultural industries of both these countries, with enormous economic and social benefit to them. Prof. Kearney, in the course of a speech which illustrated the brilliant successes of the veterinary profession in a comparatively short time, quoted Dr. Julian Huxley's "Africa View". "In Africa," wrote Huxley, "the prosperity and, indeed, the habitability of enormous areas hangs upon his (the veterinarian's) success or failure in research along the broadest biological and medical lines. . . . To be a good veterinary officer in Africa you must be a first-class biologist and you must be a knowledgeable and sympathetic anthropologist as well." These words might well form part of the terms of reference for any committee which is asked to report upon veterinary education in Great Britain or in any other country (see p. 35 of this issue). 